\title{
CLIMATE CHANGE AND FLOODS: ARE WE HEADING TOWARDS A NEW CLIMATE CYCLE IN SAHELIAN WEST AFRICA?
}

\author{
Z. NOUACEUR 1 O. MURĂRESCU
}

\begin{abstract}
Climate change and floods: are we heading towards a new climate cycle in Sahelian West Africa?. The proposed study is based on an analysis of rainfall variability and flood over more than half a century (1947-2014) in two countries in Sahel (Mauritania and Senegal). The rain analysis is based on the use of the chronological graphic method of information processing (MGCTI) of „Matrice Bertin” type. Applied to rainfall-relayed data, this method allows, in a first stage, the analysis of the spatiotemporal distribution of the meteorological parameter, then, in a second stage, the determination of data on cycle changes, if there are manifest cyclic, due to the regional analysis. The results demonstrate that at the end of the Sahelian climatic drought and a return of rains confirmed over the last decade of the studied period (1947-2014).
\end{abstract}

Keywords: Climate change, Variability, Rain, Sahel, Flood.

\section{INTRODUCTION}

The results of different studies of rainfall trends show that climate change has resulted in increased precipitation and recurrence of extreme events (Min et al., 2011, Westra et al., 2014, Donat et al., 2016). Panthou et al., 2014, showed an increase in the intensity of rainfall patterns. Conforming to an analysis of satellite data covering the period 1982-2016, a team of researchers (Taylor et al., 2017) has highlighted a dramatic increase in the frequency of extreme storms in the Sahel (Meso-scale convective system, in relation to with current climate change; the Mesoscale Convective System (MCS) can be defined as a cloud system occurring in association with thunderstorms producing a continuous zone of precipitation of horizontal extension of the order of $100 \mathrm{~km}$ or more in at least one direction Thomas Fiolleau, 2011). The results show an increase in observation frequencies of 3 to 4 more important before the study period with an estimate of 80 storms today over the 4 months of monsoon against 20 to 30 previously. Given this new climatic situation, a probable increase in extreme events and particularly floods is expected.

\footnotetext{
${ }^{1}$ UMR CNRS 6266 IDEES, University of Rouen, France; zeineddine.nouaceur@univ-rouen.fr.

2 "Valahia" University, Department of Geography, Târgovişte, Romania; ovidiu_murarescu@yahoo.com.
} 
Thus, according to the World Meteorological Organization, floods are the most observed extreme phenomenon during the decade 2001 - 2010 (WMO, 2013a and $b$ ). This phenomenon has affected many parts of the world and has hundreds or even thousands of victims. For the year 2016, nearly 23.5 million people were displaced by extreme weather-related disasters (mainly storms and floods in the Asia-Pacific region) (WMO, 2016).

In the Sahelian West Africa, in 2003, the floods caused the death of dozens of people and the loss of crops in Burkina Faso, Mali, Mauritania, Niger and Senegal. During the winter of 2005, in the latter country, major floods caused serious material damage. The entire region suffered again in August 2007 due to the late monsoon and heavy rains in this part of West Africa. This scenario was repeated again in 2008, 2009 and 2012 when the Niger River reached a record never equaled in Niamey and Locoja (Sighomnoul D. et al., 2012).

In 2016, the threat is still present since the authority of the river recorded a record level never reached since 1957 on a tributary of the Niger River. In September 2017, the scenario is renewed once again but it is much more tragic this time, the heavy rains that fell on the Niger during the rainy season made 44 dead and more than 700000 victims. The human toll is also heavy outside the Sahelian zone, with 500 dead and more than 800 missing in Sierra Leone, following heavy landslides and landslides caused by intense rains and the worst floods in the world, the capital Freetown.

Are these major events the beginnings of a confirmed climate change? Are they the result of a lack of control over the problems of urbanization and development, as well as an accelerated anthropic colonization which upsets the balance of natural environments? The debate on this subject is still lively in the scientific community and there is still hesitation to evoke large-scale climate changes throughout the Sahelian region.

\section{SITUATION DATA AND METHODS}

The objective of this article is to analyze the rainfall trend over more than half a century in Sahelian Africa (Senegal and Mauritania). Twenty stations with a common measurement period were chosen for this study (1947-2014) (fig. 1). Data from national meteorological networks (National Office of Meteorology, for Mauritania http://onm.mr/- and the National Agency of Civil Aviation and Meteorology ANACM, for Senegal - http://www.anacim.sn/) have been supplemented by information collected on the NCDC (National Climatic Data Center) website (http://www.ncdc.noaa.gov). Statistical data on flooding has been provided by The International Disaster Data Base (http://www.emdat.be/).

The method used will be the „Bertin Matrix” chronological information processing method (MGCTI) (Nouaceur et al., 2013) applied to precipitation data; this method firstly analyzes the spatio-temporal distribution and then determines 
the dates of cycle changes, if there are obvious cyclicities thanks to the regional analysis (this approach is explained in the table below, as second step of this procedure).

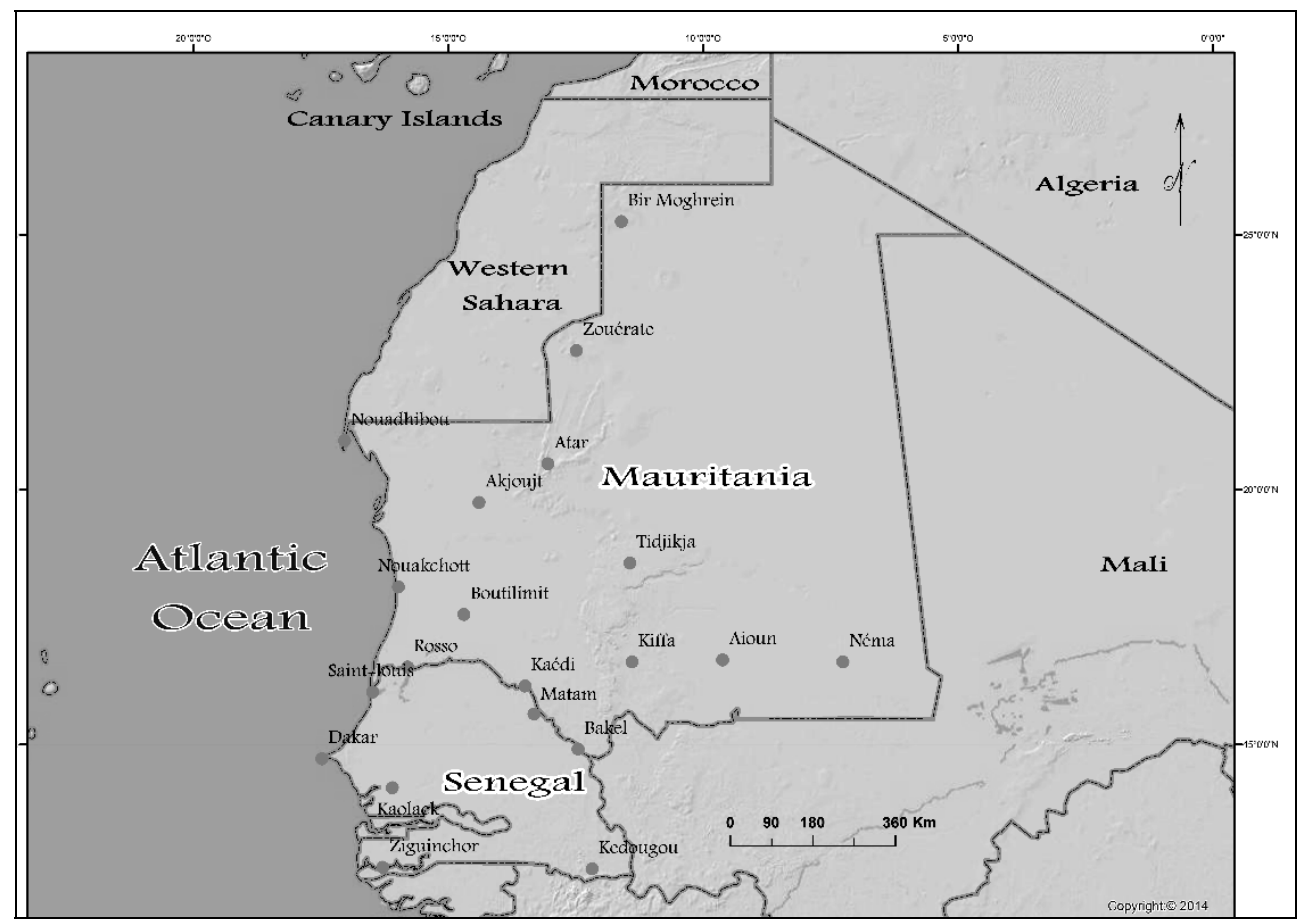

Fig. 1. Locations of the 20 weather stations

In order to determine the pluviometric tendency at the different stations, a graphic chronological data processing method of the "Matrice Bertin" type (MCGTI) has been applied to the annual data (Nouaceur \& al 2013).

This method consists in making - during a first step - a classification per year and per station related to the limit values (Q1, Q2, Q3 and Q4) calculated for all the stations and for all the series (Table 2).

The years of the first quintile $(\mathrm{Q} 1)$ with their limit value are considered very deficient (in point of rain). The years situated between the first and the second quintile (Q2) are considered deficient. The years whose pluviometric height is comprised between the second quintile and the average are normal, with a dry or humid tendency. In between the median interval and the third quintile (Q3) the years are normal, with a rainy tendency. The interval from the third to the fourth quintile (Q4) comprises years with a rainy tendency. Finally, all the years whose pluviometric total is above that of the fourth quintile are considered excessive rainy.

During a second step, the projection of the results obtained after the first data processing on a colored graph (the color varying according to the position of 
the annual pluviometric accumulation in relation to the limit values) allows for the visualization of the evolution of the climatic parameter according to two dimensions (time and space). In order to determine the gaps and the characteristic periods, a number varying between 1 (very dry year) and 5 (very humid year) has been attributed to each year, according to the already determined characteristic features. The sum of the numbers of all the stations for each year is centered and reduced, which allows for the obtaining of an index varying from +1.72 for a very humid year to -1.72 for a very dry year.

\section{RESULTS}

The results of statistical and graphical rainfall treatments confirm a marked evolution by different rainfall cycles structured in three major periods (fig. 2).

\section{The „fat cow” period (1947-1969).}

A wet period is visible on the matrix of the two countries between 1947 and 1969. This phase of nearly a quarter of a century is described as wet. It is known in the Sahel as the period of "fat cows" by allusion to the availability of pastures for the breeders of the region. The number of deficit years according to the regional index is very low. There are three deficit years for Senegal (1948, 1959 and 1964). For Mauritania, the years 1953, 1959, 1960 and 1969 show a negative regional index.

The Sahelian drought period (1970-1989 for Mauritania and 1970-1998 for Senegal).

From 1970, a new drier climate phase began, extending until 1989 for Mauritania and until 1998 for Senegal. This period is marked by a severe drought that has affected the entire Sahel region.

For Mauritania, the succession of dry years is uninterrupted between 1970 and 1985 with a character of extreme severity for the years 1971, 1972, 1973, 1977, 1982 and 1983. During these years the regional index has exceeded -1.5.

For Senegal, the drought period is longer and extends over 29 years (19701998). During this cycle, four years have a positive index (1975, 1978, 1981 and 1985).

\section{Senegal.}

The return period of the rains from 1990 for Mauritania and 1999 for

The Graph Matrix clearly shows the change in trend of Sahelian rainfall. This is materialized by a greater frequency of years with a positive regional index over the last period of the rainfall series.

For Mauritania the return of rains is carried out according to two phases. The first (between 1989 and 2002) is marked by considerable variability. The cycles show that wet years (with a positive regional index) generally follow two or 
a dry year (with a negative index). This is the case, for example, between the year 1991 (index +1.25 ) and the year 1992 (index -1.66). The second period between 2003 and 2014 is less mixed. The number of wet years (with a positive regional index) is greater (eight wet years versus four dry years). The annual variability is less marked since the succession of wet years is more continuous over time (for example, between 2008 and 2012, the regional index remained positive).
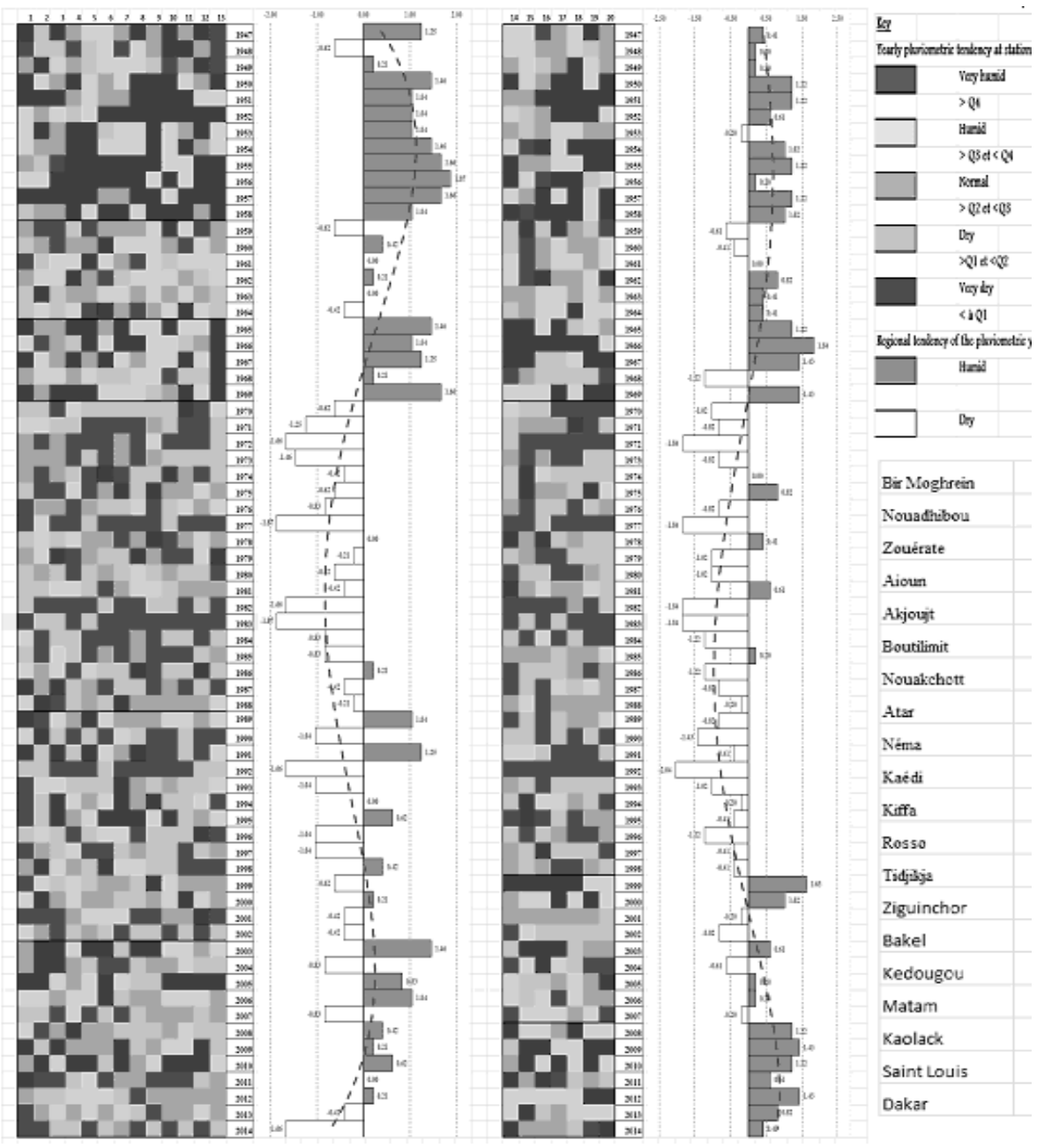

Fig. 2. MGCTI Classification of annual precipitation according to quintiles Q1, Q2, Q3, Q4 and Q5 (measurement period from 1947 to 2014)

For Senegal, the return of the rains is also marked by two cycles. The first cycle is between 1999 and 2007. During this period, there are five wet years and four 
dry years. The other peculiarity of this phase is the existence of a low annual variability (succession of years with positive and negative indices). This is the case, for example, for the years 1999 (index +1.63) and the year 2000 (index + 1.02) and the years 2001 and 2002 (respectively -0.20 and -0.82 ).

The second period is more homogeneous, it shows a clearly established cycle change. Years with a positive regional index follow one another for seven years (from 2008 to 2014).

\section{DISCUSSION AND CONCLUSION}

The analysis of the rainfall trend shows that after the long Sahelian drought, the rains are back on this part of West Africa. The map of events recorded between 1985 and 2017 shows this new trend.

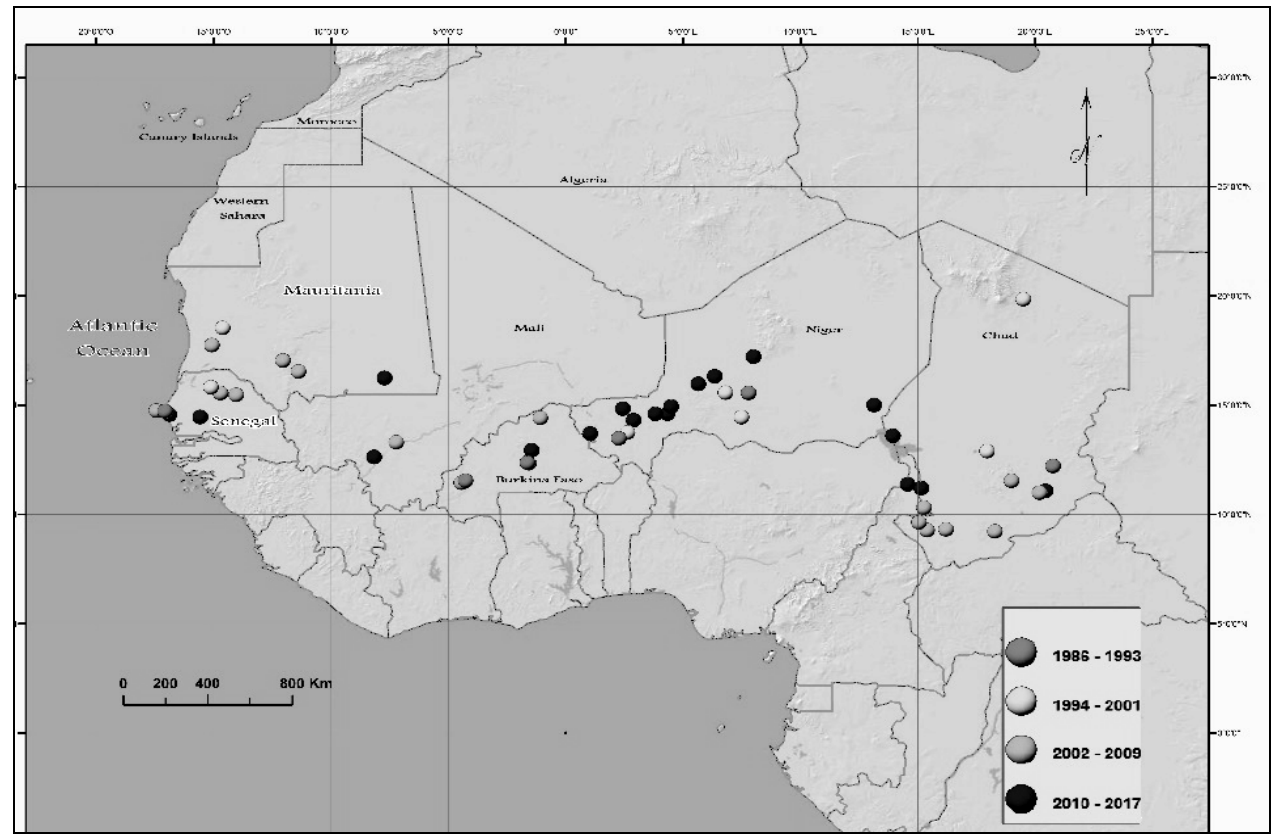

Fig. 3. Location and dates of floods in the Sahel region (data source: Em-Dat http://www.emdat.be/)

One can note that the number of events increases from the year 2000 and is extended to the entire region. Indeed, $70 \%$ of the floods occurred during the period 2002-2017 (36.53\% between 2002 and 2009 and 32.69\% between 2010 and 2017).

Table 1 also shows that $74 \%$ of deaths related to flood events occurred during this last period. We also note that $71 \%$ of people affected over the same period.

We can conclude that the Sahelian climate dryness is a past event and that the 
rainfall cycle that is observed today is different because it is characterized by a wetter trend.

Table 1. Consequences of the 1986-2017 floods in the Sahel region (source of data: EmDat - http://www.emdat.be/)

\begin{tabular}{|c|c|c|c|c|}
\hline Period & Dead & Displaced & Affected & Number of events \\
\hline $2010-2017$ & 36 & 15 & 21 & 33 \\
\hline $2002-2009$ & 38 & 51 & 50 & 37 \\
\hline $1994-2001$ & 17 & 16 & 16 & 17 \\
\hline $1986-1993$ & 9 & 18 & 13 & 13 \\
\hline
\end{tabular}

We consider, however, that the inter-annual rainfall variability is consistent with the climatic character of this region of Africa (the coefficient of variation of rainfall in this region is one of the highest in Africa).

\section{REFERENCES}

1. Donat, M. G., Lowry, A. L., Alexander, L. V., O'Gorman, P. A. \& Maher, N. (2016), More extreme precipitation in the world's dry and wet regions. Nat. Clim. Chang. 6, 508-513.

2. Fiolleau T. (2010), Cycle de vie des systèmes convectifs de mousson dans les régions tropicales: préparation à la mission Megha-Tropiques, Thèse préparée au Laboratoire de Météorologie Dynamique, Ecole Polytechnique, 211 pages.

3. Min, S.-K., Zhang, X., Zwiers, F. W. \& Hegerl, G. C. (2011), Human contribution to more-intense precipitation extremes. Nature 470, 378-381.

4. Nouaceur Z, Laignel B, Turki I. (2013), Changements climatiques au Maghreb: vers des conditions plus humides et plus chaudes sur le littoral algérien?, Physio-Géo, Volume 7; http://physio-geo.revues.org/3686; DOI: 10.4000/physio-geo.3686.

5. Panthou, G., Vischel, T. \& Lebel, T. (2014), Recent trends in the regime of extreme rainfall in the Central Sahel. Int. J. Climatol. 34, 3998-4006.

6. Sighomnoul D., Tanimoun B., Alio A., Zomodo L., Ilia A., Olomoda I., Coulibaly B. (2012), Crue exceptionnelle et inondations au cours des mois d'août et septembre 2012 dans le Niger moyen inférieur, http://www.hydrosciences.fr/ sierem/produits/biblio/ Nov. 2012, pdf.

7. Taylor C. M., Belušić D., Guichard F., Parker D. J., Vischel T., Bock O., Harris Phil P., Janicot S., Klein C., Panthou G. (2017), Frequency of extreme Sahelian storms tripled since 1982 in satellite observations, Nature 544, 475-478 (27 April 2017), doi:10.1038/nature22069.

8. Westra, S. \& al (2014), Future changes to the intensity and frequency of shortduration extreme rainfall. Rev. Geophys. 52, 522-555.

9. OMM, 2016, https://public.wmo.int/fr/

10. OMM, 2013 a, Déclaration de l'OMM sur l'état du climat en 2012, no. 1108, 32 pages livre ou rapport.

11. OMM, 2013 b, Déclaration de l'OMM sur l'état du climat en 2012, no. 1119, 15 pages livre ou rapport. 